\title{
Deliverability equation in pseudo-steady state for fractured vertical well in tight gas
}

\author{
Shaoyuan $\mathrm{Mo}^{1} \cdot$ Shunli $^{\mathrm{He}}{ }^{1} \cdot \operatorname{Gang} \mathrm{Lei}^{1} \cdot$ Shaohua Gai $^{1}$
}

Received: 11 October 2014/Accepted: 22 March 2015/Published online: 9 April 2015

(c) The Author(s) 2015. This article is published with open access at Springerlink.com

\begin{abstract}
Based on non-Darcy flow theory in tight gas reservoirs, a new deliverability equation of fractured vertical gas well in pseudo-steady state is presented with the consideration of the stress-sensitive effect, and the open flow capacity calculation formula of gas well has been also derived. With the new deliverability equation, the effects of stress-sensitive coefficient, fracture parameters and matrix permeability on the productivity of gas well have been analyzed. The computation across an instance shows that due to the stress-sensitive effect, the IPR curves bend over to the pressure axis and the productivity of gas well is lower than that derived from the equation without consideration of stress-sensitive effect under the same pressure drop. As the stress-sensitive coefficient increasing, the well productivity becomes lower, the decline rate of production is higher and the IPR curve bends over in earlier stage with a greater bending. Besides, the productivity is affected by and has a positive correlation with the length and conductivity of fracture, namely that it becomes lower as the length and conductivity of fracture decreasing. Matrix permeability has an apparent impact on the productivity. If matrix permeability is extremely low, gas well cannot achieve the industrial production even after fracturing. As the matrix permeability increasing, stimulation results are significant.
\end{abstract}

Keywords Tight gas - Pseudo-steady state $\cdot$ Non-Darcy flow $\cdot$ Stress-sensitive effect . Fractured vertical well

Shaoyuan Mo

Stanley_msy@163.com

1 MOE Key Laboratory of Petroleum Engineering, China University of Petroleum, Beijing, China

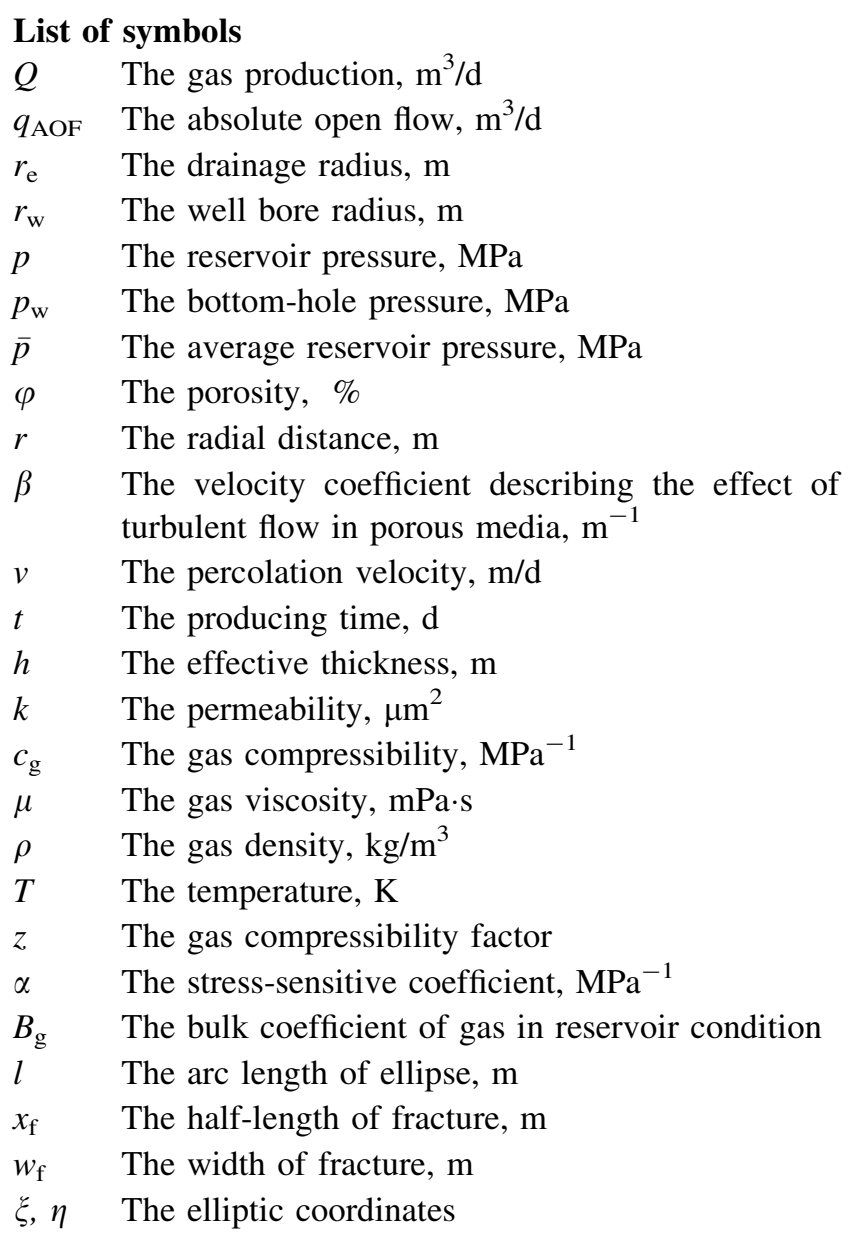

\section{Subscript}

$0 \quad$ Initial moments

f Fracture

sc Standard condition

g Gas

e Edge/boundary 


\section{Introduction}

Tight gas reservoirs have features of tiny pores, narrow throats and extremely low permeability. Wells produce at a low natural productivity so that most of wells need the stimulation treatment of fracturing. Recently, the performance of fractured vertical well has been widely studied by many researchers. With conformal transformation, Wang et al. (2003) and Jiang (2001) derived the deliverability equation of fractured vertical well and studied the corresponding pressure performance. Li et al. (2008) established the trinomial deliverability equation of fractured vertical gas well in ultra-low-permeability reservoirs by linear regression with bottom-hole pressure and gas production. Yang et al. (2003) proposed a model by considering the gas flow in reservoirs after fracturing as a combination of radial flow and linear flow and obtained the deliverability equation by integral calculation. In their study, the effects of fracture length, effective permeability and effective thickness on the production after fracturing were investigated. Yin et al. (2005) built up a mathematic model of bilinear flow for fractured vertical well and presented the solution. They also plotted and analyzed the theoretical IPR curves of fractured vertical well. Using elliptic flow model, Li et al. (2005) derived the deliverability equation of fractured vertical well with the consideration of threshold pressure gradient. Based on the theory of steady-state flow, Xiong et al. (2012) used the concept of pseudo-pressure to obtain the deliverability equation for predicting the performance of fractured vertical well in low-permeability gas reservoirs. The equation in their study featured the assumptions of finite conductivity fracture and the consideration of threshold pressure, slippage effect and stress sensitivity. Based on the characteristics and flow law of ellipse system, Luo et al. (2005) proceeded from the generalized Darcy law and synthesized the flow inside and outside the fracture to derive the deliverability equation in steady state for gas reservoirs and obtain the corresponding open flow capacity of fractured vertical gas well. According to the concept of disturbance ellipse and the idea of equivalent rectangle system, Zhou et al. (2009) gained the productivity predictions for the gas well after fracturing in low-permeability reservoirs and plotted the corresponding IPR curves for analysis. Study on productivity of fractured vertical well in above documents all contain the assumptions that boundary conditions are constant pressure and the flow is in steady state, which cannot be appropriate for the pseudo-steady state in reservoirs.

During the depletion in oil or gas reservoirs, flow in pseudo-steady state begins when the pressure wave reaches the closed boundary with the feature that the decrements of pressure at points from borehole walls to boundary gradually tend to be the same. Thus, it is significant for the development of tight gas to investigate the characteristics of IPR curve in this pseudo-steady state. Lian et al. (2013) derived a deliverability equation in pseudo-steady state for oil reservoirs with closed outer boundary. They considered the effects of stress sensitivity and degasification in bottom, and also investigated the stress-sensitive effect on production. Li et al. (2009) took the characteristics of non-linear flow into account to derive the deliverability equation in pseudo-steady state for gas well. Liao (1998) investigated the characteristics of pressure response in pseudo-steady state of deviated wells by considering the oil reservoirs as dual porous media. In this paper, a percolation model of pseudosteady flow with the consideration of stress-sensitive effect was proposed to derive a deliverability equation of fractured vertical gas well featuring the non-linear flow of gas. The analysis we made on the effects of stress-sensitive coefficient, matrix permeability, fracture length and fracture conductivity on the productivity of fractured vertical gas well is significant for the tight gas development.

\section{Model establishment}

\section{Assumptions}

Fracturing for vertical gas well induces the decrease of percolation resistance and variation of flow pattern in which the gas flow is pseudo-radial inside the fracture and linear outside the fracture (Abbaszadeh and Hegeman 1990). Assumptions specifically include the following: (1) formation thickness is equal, outer boundary is closed, production rate is constant and percolation reached the pseudo-steady state. (2) Vertical fracture is symmetrical about the borehole and vertically penetrating the formation. (3) Flow inside the fracture is one-way turbulent and gas flowing to borehole is only along the fracture. (4) Flow outside the fracture is pseudo-radial; isobars are elliptical and perpendicularly crossed by streamlines. (5) The damage to fracture surface is not considered.

\section{Flow outside the fracture}

During the production of fractured vertical well, elliptical percolation in 2D plane is induced, namely that elliptical isobars and corresponding conjugate hyperbolic streamlines form by focusing on end points of fracture. The relation between Cartesian coordinates and elliptic coordinates can be written as

$x=x_{\mathrm{f}} \operatorname{ch} \xi \cos \eta ; y=x_{\mathrm{f}} \operatorname{sh} \xi \sin \eta$.

By Eq. (1), equations of elliptical isobars and hyperbolic streamlines can be obtained and written as below 


$$
\left\{\begin{array}{l}
\frac{x^{2}}{\left(x_{\mathrm{f}} \operatorname{ch} \xi\right)^{2}}+\frac{y^{2}}{\left(x_{\mathrm{f}} \operatorname{sh} \xi\right)^{2}}=1 \\
\frac{x^{2}}{\left(x_{\mathrm{f}} \cos \eta\right)^{2}}-\frac{y^{2}}{\left(x_{\mathrm{f}} \sin \eta\right)^{2}}=1
\end{array} .\right.
$$

Based on the concept of disturbance ellipse, elliptical isobars can be described by equivalent rectangle patterns as follows.

$\bar{x}=x_{\mathrm{f}} \operatorname{ch} \xi ; \quad \bar{y}=\frac{2}{\pi} \int_{0}^{\pi / 2} x_{\mathrm{f}} \operatorname{sh} \xi \sin \eta \mathrm{d} \eta=\frac{2 x_{\mathrm{f}}}{\pi} \operatorname{sh} \xi$

In consideration of the stress-sensitive effect and the nonlinear flow in tight gas, the equation of the flow to fracture is written as

$\frac{\mathrm{d} p}{\mathrm{~d} y}=\frac{\mu}{k_{0} e^{\alpha\left(p-p_{0}\right)}} v+\beta \rho v^{2}$.

According to the definition of gas isothermal compressibility, the total elastic volume in control area of a certain gas well is as follows

$V(t)=c_{\mathrm{g}} V_{t}\left(p_{0}-\bar{p}(t)\right)$

where

$$
\begin{aligned}
& V(t) \approx \pi\left(x_{\mathrm{f}}^{2} \operatorname{sh} \xi_{\mathrm{e}} \operatorname{ch} \xi_{\mathrm{e}}-x_{\mathrm{f}} w_{\mathrm{f}}\right) h \\
& \xi_{\mathrm{e}}=\ln \left[r_{\mathrm{e}} / x_{\mathrm{f}}+\sqrt{\left(r_{\mathrm{e}} / x_{\mathrm{f}}\right)^{2}-1}\right] .
\end{aligned}
$$

And the gas production can be expressed as

$$
\begin{aligned}
q_{\mathrm{sc}}(t) B_{\mathrm{g}} & =\frac{\mathrm{d} V(t)}{\mathrm{d} t}=-c_{\mathrm{g}} V_{\mathrm{t}} \frac{\mathrm{d} \bar{p}(t)}{\mathrm{d} t} \\
& =-c_{\mathrm{g}} \pi\left(\frac{x_{\mathrm{f}}^{2} \operatorname{sh}\left(2 \xi_{\mathrm{e}}\right)}{2}-x_{\mathrm{f}} w_{\mathrm{f}}\right) h \frac{\mathrm{d} \bar{p}(t)}{\mathrm{d} t} .
\end{aligned}
$$

Rate of flow through any isopiestic pressure section in the well controlling area is expressed as

$q_{\mathrm{sc}}(\xi, t) B_{\mathrm{g}}=-c_{\mathrm{g}} \pi\left(\frac{x_{\mathrm{f}}^{2} \operatorname{sh}\left(2 \xi_{\mathrm{e}}\right)-x_{\mathrm{f}}^{2} \operatorname{sh}(2 \xi)}{2}\right) h \frac{\mathrm{d} \bar{p}(t)}{\mathrm{d} t}$.

Due to $x_{\mathrm{f}} \operatorname{sh}\left(2 \xi_{\mathrm{e}}\right) \gg 2 w_{\mathrm{f}}$, it can obtain Eq. (8) as

$$
\begin{aligned}
q_{\mathrm{sc}}(\xi, t) & =\frac{x_{\mathrm{f}}^{2} \operatorname{sh}\left(2 \xi_{\mathrm{e}}\right)-x_{\mathrm{f}}^{2} \operatorname{sh}(2 \xi)}{x_{\mathrm{f}}^{2} \operatorname{sh}\left(2 \xi_{\mathrm{e}}\right)-2 x_{\mathrm{f}} w_{\mathrm{f}}} q_{\mathrm{sc}}(t) \\
& \approx\left(1-\frac{\operatorname{sh}(2 \xi)}{\operatorname{sh}\left(2 \xi_{\mathrm{e}}\right)}\right) q_{\mathrm{sc}}(t) .
\end{aligned}
$$

Transform $q_{\mathrm{sc}}(\xi, t)$ to $q_{\mathrm{g}}$ in subsurface conditions

$q_{\mathrm{g}}=\frac{p_{\mathrm{sc}} z T}{T_{\mathrm{sc}} p}\left(1-\frac{\operatorname{sh}(2 \xi)}{\operatorname{sh}\left(2 \xi_{\mathrm{e}}\right)}\right) q_{\mathrm{sc}}(t)$.

For an isopiestic ellipse with a semi-major axis of $x_{\mathrm{f}} \mathrm{ch} \xi$ and a semi-minor axis of $x_{\mathrm{f}} \mathrm{sh} \xi$, the flow velocity can be written as $v=\frac{q_{\mathrm{g}}}{l(\xi) h}$

where

$l(\xi)=4 x_{\mathrm{f}} \operatorname{ch} \xi \int_{0}^{\pi} \sqrt{1-\left(1-t h^{2} \xi\right) \sin ^{2} t} \mathrm{~d} t$.

With the chain rule, we can obtain

$\frac{\mathrm{d} p}{\mathrm{~d} y}=\frac{\mathrm{d} p}{\mathrm{~d} \bar{y}}=\frac{\mathrm{d} p}{\mathrm{~d} \xi} \frac{d \xi}{d \bar{y}}=\frac{\pi}{2 x_{\mathrm{f}} \operatorname{ch} \xi} \frac{\mathrm{d} p}{\mathrm{~d} \xi}$.

Introduce the variable of pseudo-pressure $U(p)=\int_{p_{0}}^{p} \frac{p e^{\alpha\left(p-p_{0}\right)}}{\mu z} \mathrm{~d} p$, and substitute Eqs. (9), (10) and (11) into Eq. (4), we can obtain

$\mathrm{d} U=\frac{4 x_{\mathrm{f}} p_{\mathrm{sc}} T}{\pi T_{\mathrm{sc}}}\left(\begin{array}{l}\frac{q_{\mathrm{sc}}}{k_{0} h}\left(1-\frac{\operatorname{sh}(2 \xi)}{\operatorname{sh}\left(2 \xi_{\mathrm{e}}\right)}\right) \frac{\operatorname{ch} \xi}{l(\xi)} \\ +\frac{\beta \rho_{\mathrm{sc}} q_{\mathrm{s}}^{2} e^{\alpha\left(\bar{p}-p_{0}\right)}}{\bar{\mu} h^{2} l^{2}(\xi)}\left(1-\frac{\operatorname{sh}(2 \xi)}{\operatorname{sh}\left(2 \xi_{\mathrm{e}}\right)}\right)^{2} \operatorname{ch} \xi\end{array}\right) \mathrm{d} \xi$.

With the boundary conditions, in the boundary of well controlling area, there is

$U_{\mathrm{e}}=\left.U\right|_{r=r_{\mathrm{e}}}=\int_{p_{0}}^{p_{\mathrm{e}}} \frac{p e^{\alpha\left(p-p_{0}\right)}}{\mu z} \mathrm{~d} p$.

Solving Eq. (13), the pressure in an isopiestic ellipse with semi-major axis of $x_{\mathrm{f}} \mathrm{ch} \xi$ and semi-minor axis of $x_{\mathrm{f}} \mathrm{sh} \xi$ can be obtained

$$
\begin{aligned}
U(\xi)= & U_{\mathrm{e}}-\frac{4 x_{\mathrm{f}} p_{\mathrm{sc}} T}{\pi T_{\mathrm{sc}}} \\
& \times\left(\begin{array}{l}
\frac{q_{\mathrm{sc}}}{k_{0} h} \int_{\xi}^{\xi_{\mathrm{e}}}\left(1-\frac{\operatorname{sh}(2 \xi)}{\operatorname{sh}\left(2 \xi_{\mathrm{e}}\right)}\right) \frac{\mathrm{ch} \xi}{l(\xi)} \mathrm{d} \xi \\
+\frac{\beta \rho_{\mathrm{sc}} q_{\mathrm{sc}}^{2} e^{\alpha\left(\bar{p}-p_{0}\right)}}{\bar{\mu} h^{2}} \int_{\xi}^{\xi_{\mathrm{e}}} \frac{\operatorname{ch} \xi}{l^{2}(\xi)}\left(1-\frac{\operatorname{sh}(2 \xi)}{\operatorname{sh}\left(2 \xi_{\mathrm{e}}\right)}\right)^{2} \mathrm{~d} \xi
\end{array}\right) .
\end{aligned}
$$

The average pseudo-pressure in gas supply area is

$$
\bar{U}=\frac{\int_{0}^{\xi_{\mathrm{e}}}\left(\operatorname{sh}^{2} \xi+\mathrm{ch}^{2} \xi\right) U(\xi) \mathrm{d} \xi}{\operatorname{sh}\left(\xi_{\mathrm{e}}\right) \operatorname{ch}\left(\xi_{\mathrm{e}}\right)} .
$$

Substitute Eq. (15) into Eq. (14) to obtain Eq. (16)

$$
\begin{aligned}
\bar{U}= & U_{\mathrm{e}}-\frac{8 x_{\mathrm{f}} p_{\mathrm{sc}} T}{\pi T_{\mathrm{sc}} \mathrm{sh} \xi_{\mathrm{e}}} \int_{0}^{\xi_{\mathrm{e}}} \\
& \times\left(\begin{array}{c}
\frac{q_{\mathrm{sc}}\left(\mathrm{sh}^{2} \xi+\mathrm{ch}^{2} \xi\right)}{k_{0} h} \int_{\xi}^{\xi_{\mathrm{c}}}\left(1-\frac{\operatorname{sh}\left(2 \xi^{\prime}\right)}{\operatorname{sh}\left(2 \xi_{\mathrm{e}}\right)}\right) \frac{\mathrm{ch}^{\prime}}{l\left(\xi^{\prime}\right)} \mathrm{d} \xi^{\prime}+ \\
\frac{\beta \rho_{\mathrm{sc}} q_{\mathrm{s}}^{2} e^{\alpha\left(\bar{p}-p_{0}\right)}}{\left(\frac{\tilde{\mu} h^{2}}{\left(\mathrm{sh}^{2} \xi+\mathrm{ch}^{2} \xi\right)}\right)} \int_{\xi}^{\xi_{\mathrm{e}}}\left(1-\frac{\operatorname{sh}\left(2 \xi^{\prime}\right)}{\operatorname{sh}\left(2 \xi_{\mathrm{e}}\right)}\right)^{2} \frac{\mathrm{ch} \xi^{\prime}}{l^{2}\left(\xi^{\prime}\right)} \mathrm{d} \xi^{\prime}
\end{array}\right) \mathrm{d} \xi .
\end{aligned}
$$


With Eq. (16), we can obtain the pseudo-pressure $U_{\mathrm{w} 1}$ in $\xi=0$. And combine $U_{\mathrm{w} 1}$ and Eq. (16), we can obtain the follow equation

$$
\bar{U}-U_{\mathrm{w} 1}=A q_{\mathrm{sc}}+B q_{\mathrm{sc}}^{2}
$$

where

$$
\begin{aligned}
A= & \frac{4 x_{\mathrm{f}} p_{\mathrm{sc}} T}{\pi k_{0} h T_{\mathrm{sc}}} \int_{0}^{\xi_{e}}\left(1-\frac{\operatorname{sh}(2 \xi)}{\operatorname{sh}\left(2 \xi_{\mathrm{e}}\right)}\right) \frac{\mathrm{ch} \xi}{l(\xi)} \mathrm{d} \xi \\
& -\frac{8 x_{\mathrm{f}} p_{\mathrm{sc}} T}{\pi k_{0} h T_{\mathrm{sc}} \operatorname{sh}\left(2 \xi_{\mathrm{e}}\right)} \int_{0}^{\xi_{e}}\left(\mathrm{sh}^{2} \xi+\mathrm{ch}^{2} \xi\right) \\
& \times\left(\int_{\xi}^{\xi_{\mathrm{e}}}\left(1-\frac{\operatorname{sh}\left(2 \xi^{\prime}\right)}{\operatorname{sh}\left(2 \xi_{\mathrm{e}}\right)}\right) \frac{\mathrm{ch}^{\prime}}{l\left(\xi^{\prime}\right)} \mathrm{d} \xi^{\prime}\right) \mathrm{d} \xi \\
B= & \frac{4 x_{\mathrm{f}} p_{\mathrm{sc}} T}{\pi T_{\mathrm{sc}}} \frac{\beta \rho_{\mathrm{sc}} e^{\alpha\left(\bar{p}-p_{0}\right)}}{\bar{\mu} h^{2}} \int_{0}^{\xi_{\mathrm{e}}} \frac{\operatorname{ch} \xi}{l^{2}(\xi)}\left(1-\frac{\operatorname{sh}(2 \xi)}{\operatorname{sh}\left(2 \xi_{\mathrm{e}}\right)}\right)^{2} \mathrm{~d} \xi \\
& -\frac{8 x_{\mathrm{f}} p_{\mathrm{sc}} T}{\pi T_{\mathrm{sc}}} \frac{\beta \rho_{\mathrm{sc}} \alpha^{\alpha\left(\bar{p}-p_{0}\right)}}{\bar{\mu} h^{2} \operatorname{sh}\left(2 \xi_{\mathrm{e}}\right)} \int_{0}^{\xi_{\mathrm{e}}}\left(\operatorname{sh}^{2} \xi+\mathrm{ch}^{2} \xi\right) \\
& \times\left(\int_{\xi}^{\xi_{\mathrm{e}}}\left(1-\frac{\operatorname{sh}\left(2 \xi^{\prime}\right)}{\operatorname{sh}\left(2 \xi_{\mathrm{e}}\right)}\right)^{2} \frac{\operatorname{ch}^{\prime}}{l^{2}\left(\xi^{\prime}\right)} \mathrm{d} \xi^{\prime}\right) \mathrm{d} \xi .
\end{aligned}
$$

\section{Flow inside the fracture}

After flowing into the fracture, gas flows to borehole along the fracture. According to the flow formula in fracture, the below equation can be derived through integral calculation.

$U_{\mathrm{w} 1}-U_{\mathrm{w}}=A_{1} q_{\mathrm{sc}}+B_{1} q_{\mathrm{sc}}^{2}$

where

$A_{1}=\frac{p_{\mathrm{sc}} T x_{\mathrm{f}}}{4 k_{\mathrm{f}} T_{\mathrm{sc}} w_{\mathrm{f}} h} ; B_{1}=\frac{\beta \rho_{\mathrm{sc}} p_{\mathrm{sc}} T x_{\mathrm{f}} e^{\alpha\left(\bar{p}-p_{0}\right)}}{16 \bar{\mu} T_{\mathrm{sc}} w_{\mathrm{f}}^{2} h^{2}}$.

Combining the flow equations outside the fracture, Eq. (17) and inside the fracture, Eq. (18); we can obtain the Eq. (19)

$\bar{U}-U_{\mathrm{w}}=\left(A+A_{1}\right) q_{\mathrm{sc}}+\left(B+B_{1}\right) q_{\mathrm{sc}}^{2}$.

With Eq. (19), the gas production and the open flow capacity, both taking stress-sensitive permeability into account, are derived respectively as

$q_{\mathrm{sc}}=\frac{-\left(A+A_{1}\right)+\sqrt{\left(A+A_{1}\right)^{2}+4\left(B+B_{1}\right)\left(\bar{U}-U_{\mathrm{w}}\right)}}{2\left(B+B_{1}\right)}$

$q_{\mathrm{AOF}}=\frac{-\left(A+A_{1}\right)+\sqrt{\left(A+A_{1}\right)^{2}+4\left(B+B_{1}\right) \bar{U}}}{2\left(B+B_{1}\right)}$

\section{Applications and discussions}

In this section, we programmed by MATLAB to calculate the productivity of fractured vertical gas well via the equations that have been derived above across an instance where the parameters are from a tight gas in china and we also investigated the effects on gas production. The parameters of a certain tight gas in china mainly include initial pressure of $31.889 \mathrm{MPa}$, bottom-hole pressure of 16.55 MPa, average formation pressure of $31.05 \mathrm{MPa}$, effective thickness of $18.75 \mathrm{~m}$, initial absolute permeability of $0.089 \times 10^{-3} \mu \mathrm{m}^{2}$, formation temperature of $395.6 \mathrm{~K}$, average fluids viscosity of $0.027 \mathrm{mPa} \mathrm{s}$, average gas compressibility factor of 0.89 , fracture half-length of $400 \mathrm{~m}$, fracture width of $0.005 \mathrm{~m}$, fracture permeability of $40 \mu \mathrm{m}^{2}$, wellbore radius of $0.1015 \mathrm{~m}$, drainage radius of $500 \mathrm{~m}$ and stress-sensitive coefficient of $0.01 \mathrm{MPa}^{-1}$.

\section{Effect of stress-sensitive coefficient on IPR curves}

Productivity curves of fractured vertical gas well in different stress-sensitive coefficients are plotted in Fig. 1. From which we can see that as the stress-sensitive coefficients increase, well productivity decreases and the decline rate of gas production is higher, meanwhile the productivity curves bend over to the pressure axis in the earlier stage with a greater bending. This is because the larger stress-sensitive coefficient indicates more intense of stresssensitive effect to induce more pronounced decrease of permeability with the decline of reservoir pressure, which impacts significantly on well productivity (McKee et al. 1988).

\section{Effect of matrix permeability on IPR curves}

Figure 2 contains productivity curves of fractured vertical gas well in different matrix permeabilities, where the gas production under the bottom-hole pressure of $0 \mathrm{MPa}$ is the absolute open flow. Figure 2 shows that well productivity after fracturing increases apparently with the matrix

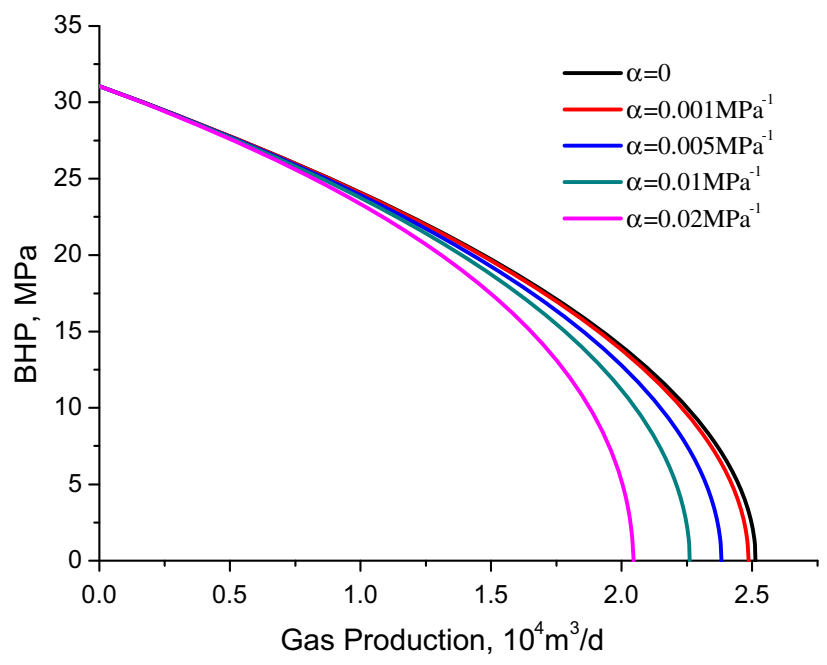

Fig. 1 The IPR curves of different stress-sensitive coefficients 


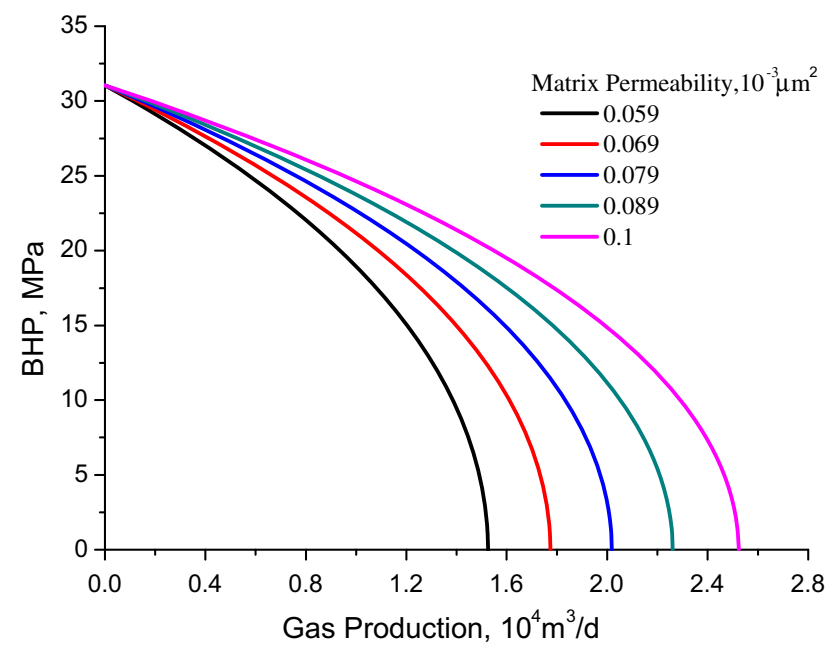

Fig. 2 The IPR curves of different matrix permeabilities

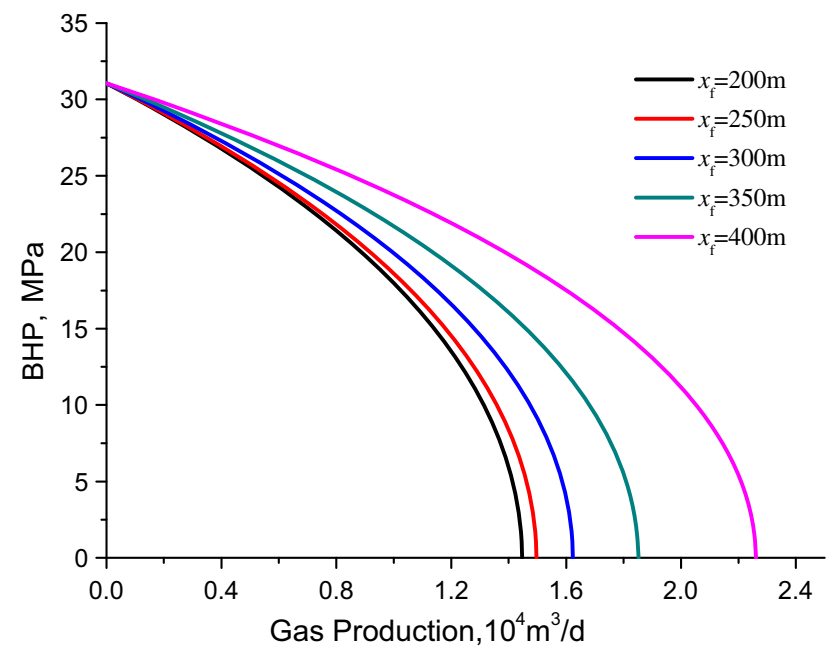

Fig. 3 The IPR curves of different fracture half-lengths

permeability. The open flow rate is $1.53 \times 10^{4} \mathrm{~m}^{3} / \mathrm{d}$ with the matrix permeability of $0.059 \times 10^{-3} \mu \mathrm{m}^{2}$ and increases to $2.52 \times 10^{4} \mathrm{~m}^{3} / \mathrm{d}$ as the matrix permeability up to $0.10 \times 10^{-3} \mu \mathrm{m}^{2}$. It indicates that extremely low matrix permeability may lead to a poor gas production that cannot reach the industrial value for exploitation even if fracturing. On the contrary, the stimulation of fracturing has a positive effect in higher matrix permeability. Thus, those gas wells in relatively high matrix permeability should be chosen for fracturing.

\section{Effects of fracture half-length and conductivity on IPR curves}

Productivity curves of fractured vertical gas well with different fracture half-lengths are displayed in Fig. 3 and those with different fracture conductivities are plotted in

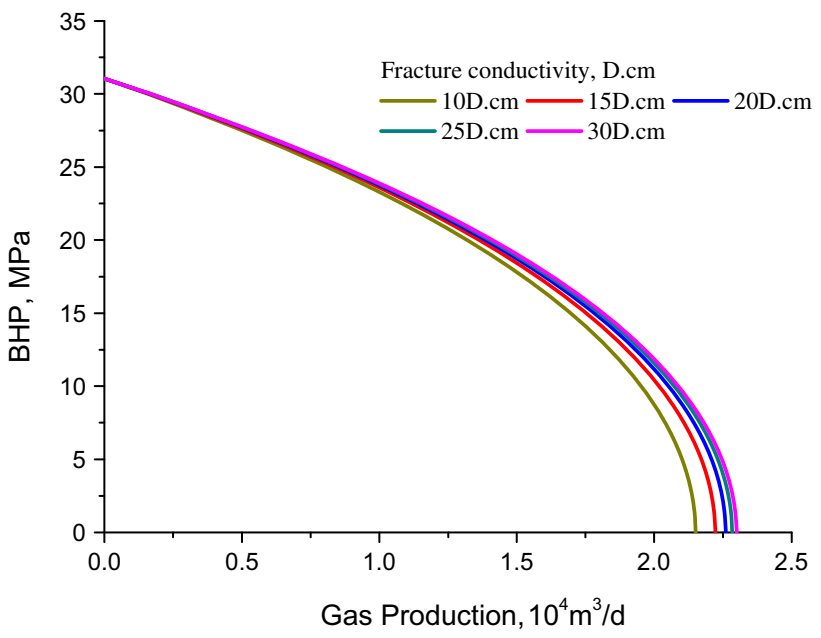

Fig. 4 The IPR curves of different fracture conductivities

Fig. 4. In general, Figs. 3 and 4 give the impressions that gas production has a positive relation with the fracture halflength and conductivity. The increase of gas production is non-linear with the linear variations of fracture half-length and conductivity. It is significant that the increment of gas production gradually ascends with the fracture half-length but descends with the fracture conductivity. Namely, increasing fracture half-length could more benefit the gas production than increasing the fracture conductivity.

\section{Effects of the factors on open flow}

The effects of stress-sensitive coefficient, matrix permeability, fracture half-length and conductivity on the open flow capacity of gas well are investigated. The analysis is shown in Table 1. It demonstrates that stress-sensitive coefficient, matrix permeability, fracture half-length and conductivity impact the open flow in varying degrees. Open flow has a positive correlation with matrix permeability, fracture half-length and conductivity, but a negative relation with stress-sensitive coefficient. In these factors we investigated, matrix permeability and fracture half-length lead the first and second place for most affecting the open flow, respectively. Meanwhile, fracture conductivity contributes the slightest impact on gas production. Thereby, an instruction is drawn that the longer fracture half-length and the choosing of gas well in favorable geological condition are primary for fracturing stimulation.

\section{Conclusions}

Productivity equations in pseudo-steady state for fractured vertical gas well embedded with the stress-sensitive effect have been derived and applied across an instance. And the effects of stress-sensitive coefficient, matrix permeability, 
Table 1 The open flow capacity of gas well with different sensitive parameters

\begin{tabular}{llllllll}
\hline $\begin{array}{l}\text { Stress-sensitive } \\
\text { coefficient }\left(\mathrm{M} \mathrm{Pa}^{-1}\right)\end{array}$ & $\begin{array}{l}\text { Open flow } \\
\left(10^{4} \mathrm{~m}^{3} / \mathrm{d}\right)\end{array}$ & $\begin{array}{l}\text { Matrix permeability } \\
\left(10^{-3} \mu \mathrm{m}^{2}\right)\end{array}$ & $\begin{array}{l}\text { Open flow } \\
\left(10^{4} \mathrm{~m}^{3} / \mathrm{d}\right)\end{array}$ & $\begin{array}{l}\text { Fracture half- } \\
\text { length }(\mathrm{m})\end{array}$ & $\begin{array}{l}\text { Open flow } \\
\left(10^{4} \mathrm{~m}^{3} / \mathrm{d}\right)\end{array}$ & $\begin{array}{l}\text { Fracture } \\
\text { conductivity } \\
\left(\mu \mathrm{m}^{2} \mathrm{~cm}\right)\end{array}$ \\
\hline 0 & 2.51 & 0.059 & 1.53 & 200 & 1.45 & 10 & $\begin{array}{l}\text { Open flow } \\
\left(10^{4} \mathrm{~m}^{3} / \mathrm{d}\right)\end{array}$ \\
0.001 & 2.49 & 0.069 & 1.77 & 250 & 1.50 & 15 & 2.15 \\
0.005 & 2.38 & 0.079 & 2.02 & 300 & 1.62 & 20 & 2.22 \\
0.01 & 2.26 & 0.089 & 2.26 & 350 & 1.85 & 25 & 2.26 \\
0.02 & 2.05 & 0.10 & 2.52 & 400 & 2.26 & 30 & 2.30 \\
\hline
\end{tabular}

fracture half-length and conductivity on gas production have been investigated, which draws a significant instruction for fracturing stimulation. Gas production and open flow are affected in different extents by stress-sensitive coefficient, matrix permeability, fracture half-length and conductivity. They are positively correlative with matrix permeability, fracture half-length and conductivity, but negatively related with stress-sensitive coefficient. In the factors we investigated, matrix permeability leads the list of the effects on gas production and open flow. The gas well in extremely low-permeability area cannot achieve the production of industrial value for exploitation even after fracturing unless multistage fracturing was conducted or complicated fractures were generated.

Open Access This article is distributed under the terms of the Creative Commons Attribution 4.0 International License (http:// creativecommons.org/licenses/by/4.0/), which permits unrestricted use, distribution, and reproduction in any medium, provided you give appropriate credit to the original author(s) and the source, provide a link to the Creative Commons license, and indicate if changes were made.

\section{References}

Abbaszadeh M, Hegeman PS (1990) Pressure-transient analysis for a slanted well in a reservoir with vertical pressure support. SPEFE, pp 277-284

Jiang T-X et al (2001) The calculation of stable Production capability of vertically fractured well. Pet Explor Dev 28(2):61-63
Li S, Li X, Zeng ZL et al (2005) W ell production evaluation of vertical fracture in low permeable reservoir. PGODD 24(1):54-56

Li W, Yu SQ, Zheng LK (2008) New method to determine the deliverability equation factor of tri-item equation for low permeability fracturing gas wells. PGODD 27(4):61-63

Li M, Xue GQ, Luo BH et al (2009) Pseudosteady-state trinomial deliverability equation and application of low permeability gas reservoir. Xinjiang Pet Geol 30(5):593-595

Lian PQ, Tan XQ, Ma CY (2013) Productivity analysis of stress sensitive reservoir in pseudo-steady state. Sci Technol Eng 13(10):2671-2675

Liao XW (1998) Discussion of slanted well test model in dual porosity reservoirs with pseudo steady state flow. Pet Explor Dev 25(5):57-61

Luo TY, Zhao JZ, Guo JC (2005) Elliptical flow method to calculate productivity of gas wells after fracturing. Nat Gas Ind 25(10):94-96

McKee CR, Bumb AC, Koenig RA (1988) Stress-dependent permeability and porosity of coal and other geologic formations. J SPE Form Eval 3(1):81-91

Wang YL, Jiang TX, Zeng B (2003) Productivity performances of hydraulically fractured gas well. Acta Pet Sinica 4(24):66-68

Xiong J, Yu LJ, Guo P (2012) Analysis on productivity equation of fractured well in low permeability gas reservoir with non-linear seepage. Nat Gas Oil 30(6):42-45

Yang ZM, Zhang S, Zhang XH et al (2003) The steady-state productivity formula after fracturing for gas wells and fracturing numerical simulation. Nat Gas Ind 23(4):74-76

Yin HJ, Liu Y, Fu CQ (2005) Productivity analysis for fractured well in low permeability reservoir. Spec Oil Gas Reserv 12(2):55-56

Zhou Q, Jiang HQ, Li ZG (2009) Deliverability calculation for gas wells with vertical fracture in low permeability reservoir 